\title{
Analysis on the behavior of line differential protective relaying with solar PV penetration
}

\author{
M. E. Yusoff, H. Hashim \\ Department of Electrical Power Engineering, National Energy University, Malaysia
}

\begin{tabular}{l}
\hline \hline Article Info \\
\hline Article history: \\
Received Feb 2, 2020 \\
Revised Apr 3, 2020 \\
Accepted Apr 18, 2020 \\
\hline Keywords: \\
Current transformer \\
Fault \\
PSSE \\
Renewable energy \\
Unit protection
\end{tabular}

\begin{abstract}
Power System Protection is very important in electrical power system as it minimizes power supply interruption to customers, and also prevents damages to electrical equipment. Lately, renewable energy (RE) penetration in power system helps to support and fulfil the increasing demand of electricity to customers. However, the contribution of power from RE such as solar photovoltaic (PV) will increase the fault level and lead to reverse power flow; thus, it will affect power system protection reliability. This paper focuses on evaluating the reliability of differential protection relay during steady state, internal and external faults conditions when the power system is without and with solar PV penetration. Steady state and three-phase symmetrical line fault will be simulated in IEEE 39 bus test system using Power System Simulation for Engineering (PSS®E) software.
\end{abstract}

Copyright $\odot 2020$ Institute of Advanced Engineering and Science. All rights reserved.

Corresponding Author:

Mas Ewani Binti Mohamed Yusoff,

Department of Electrical Power Engineering,

National Energy University,

Jalan IKRAM-UNITEN, 43000 Kajang, Selangor, Malaysia.

Email: masewani93@yahoo.com

\section{INTRODUCTION}

Power system is a combination of equipment, protection scheme and policies in order to ensure that the system is in a healthy condition despite of a fault occurrence [1]. Among the combination, protection scheme is the most essential element as it helps in fulfilling the demands needed by the customers. Protection scheme of a transmission line consists of unit protection and non-unit protection [2]. Unit protection is also known as differential protection which protects a specific electrical equipment such as a transformer, feeder and generator [3]. The principle operation of a differential protection scheme is based on Kirchhoff's current law, which is comparing the currents at all ends of the protected equipment $[4,5]$. The philosophy of unit protection is to compare the difference in the transformed current by the current transformers $(\mathrm{CT})$ at the incoming and outgoing terminals of the protected equipment [6]. Furthermore, in any power system protection, the main characteristic of differential protection is fast isolation of the faulted area in order to sustain power supply to consumers [6-10].

\section{LINE DIFFERENTIAL PROTECTION RELAY}

Line differential protection is also known as current differential protection. This type of protection is normally used as the main protection for transmission network system. Figure 1 shows the flow of secondary current in a differential protection relay. For ideal current transformers, the current difference is zero during steady state and external fault conditions. However, practically some amount of differential current will exist during steady state condition due to the charging current of a transmission line and mismatch in the characteristics of the CTs at both ends [11]. Hence in this situation, the relay is set to remain stable by having a bias setting 

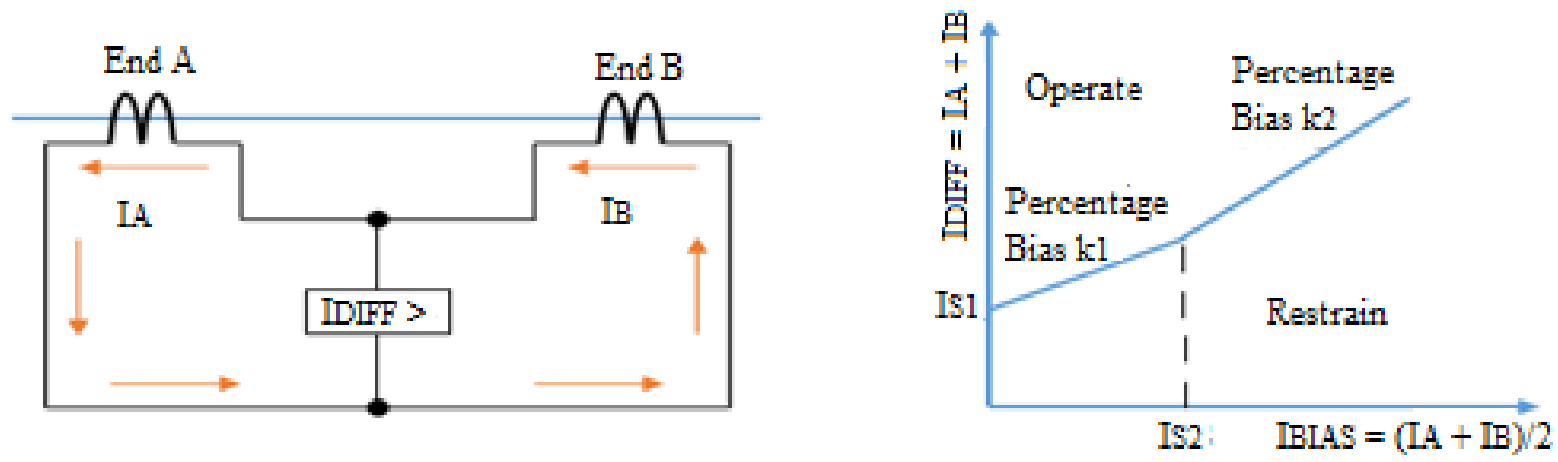

Figure 1. Circulating current system and bias protection characteristics [12]

Referring to Figure 1, when an external fault occurs, the transformed current at End A and End B with negligible difference will be flowing around the loop, thus the protection relay will not operate [13]. Nevertheless, when an internal fault occurs in the system, the interconnection between End A and End B will have some different impedance causing a deviation from the ideal case. Hence, this will increase the differential current flowing through the operating element of the protection relay [14]. Furthermore, the current at End B changes its direction; as a result, it establishes a significant differential current to operate the relay. The minimum tripping current is usually defined by the minimum relay tripping threshold and is set to be between 20-50\% of the rated CT secondary current [15]. Current differential relay can be classified into: current ratio plane characteristic and biased differential plane characteristic [16]. The objective of both characteristics is to define an operating region when respond to all types of internal faults, excluding steady state and external fault.

Biased differential characteristic is defined by calculating the bias and differential currents from the currents transformed at both ends of the transmission line. The bias current, $\mathrm{I}_{\mathrm{BIAS}}$ is obtained as half of the scalar sum of the currents at the two ends. The bias current of a transmission line can be calculated using in (1) while the differential current, $\mathrm{I}_{\mathrm{DIFF}}$ is the magnitude of the vector sum of the two end currents as shown in (2). Referring to Figure 1, $\mathrm{I}_{\mathrm{DIFF}}$ is the difference in current transformed by the CTs at End A and End B [17]:

$$
\begin{aligned}
& I_{B I A S}=\frac{\left|I_{A}\right|+\left|I_{B}\right|}{2} \\
& I_{D I F F}=\left|I_{A}+I_{B}\right|
\end{aligned}
$$

where;

$\mathrm{I}_{\mathrm{A}}$ is the local-end current;

$\mathrm{I}_{\mathrm{B}}$ is the remote-end current

Power flow is normally unidirectional from the source to consumers [18-20] with conventional generators. However, lately there is an overwhelming RE penetration such as solar PV in power system [19-22]. As a result, it is a challenge to power system protection since most of the protective relaying design is based on the assumption which is radial in nature. Therefore, due to the impact of RE to power system behavior [17-21, 23-25], the reliability of differential protection scheme needs be analyzed when the power system network is without and with RE penetration such as solar PV.

\section{RESEARCH METHODOLOGY}

IEEE 39 bus test system is modelled using PSS ${ }^{\circledR} \mathrm{E}$ software as shown in Figure 2, which consists of 10 conventional generators, 11 power transformers and 19 static loads. Figure 3 shows the overall methodology of this research work in analyzing the reliability of differential protection relay, which is being installed at each of the following selected lines:

a) The strongest line, between Bus 7 and Bus 8

b) The weakest line, between Bus 16 and Bus 19, and

c) The bottleneck line, between Bus 20 and Bus 34 .

The strongest and weakest lines are determined using voltage stability index (VSI): fast voltage stability index (FVSI) and LQP index [26]. On the other hand, the bottleneck line which is also known as 
congested line is determined through percentage of line loading. External and internal faults are applied at the chosen lines to investigate the behavior of power system and the reliability of differential protection relay. Figure 4 demonstrates the time line event of fault simulation: line fault is applied to the test system at $1 \mathrm{~s}$; the fault is cleared by tripping the faulty line at $1.10 \mathrm{~s}$; the simulation ends at $10 \mathrm{~s}$.

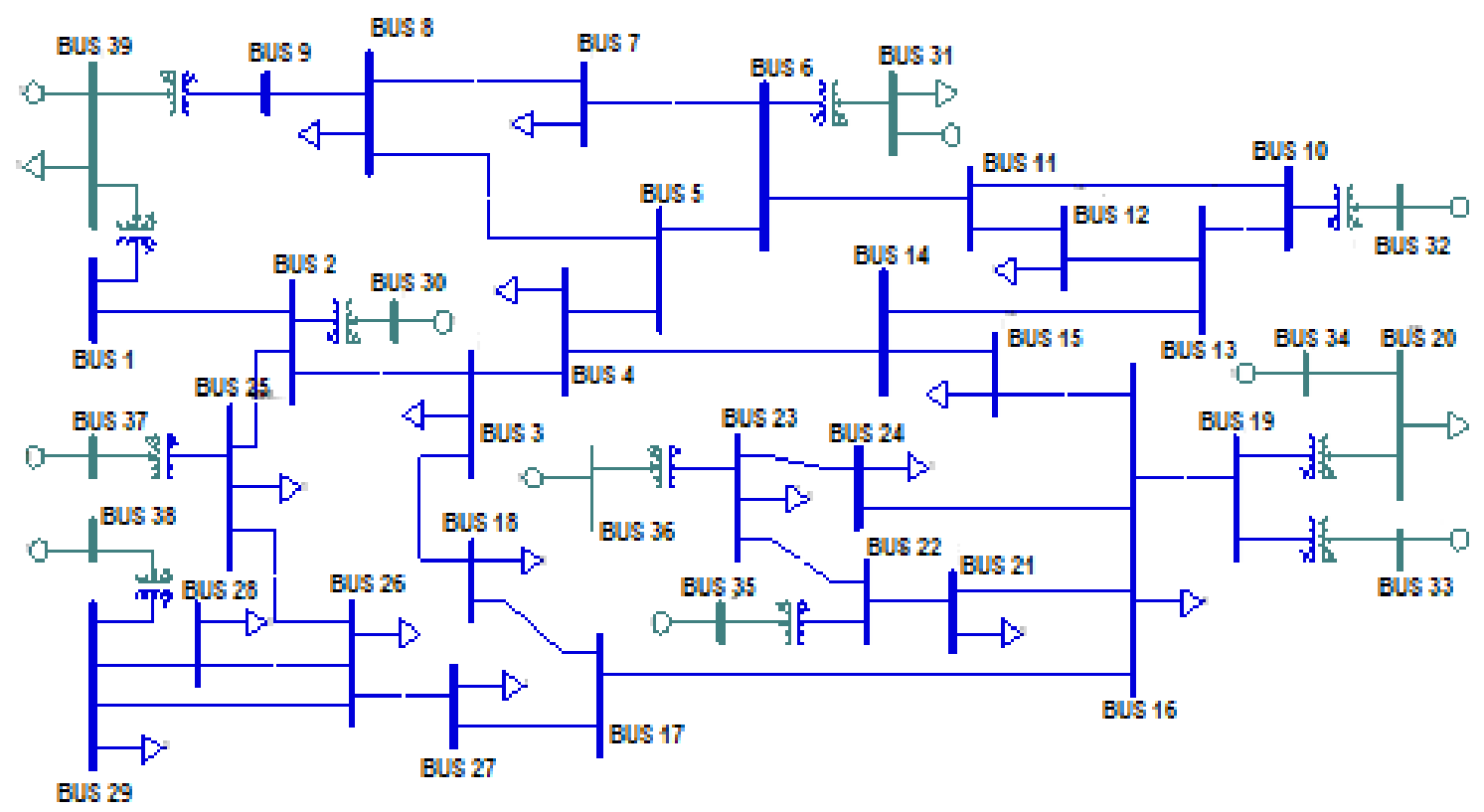

Figure 2. IEEE 39 bus test system

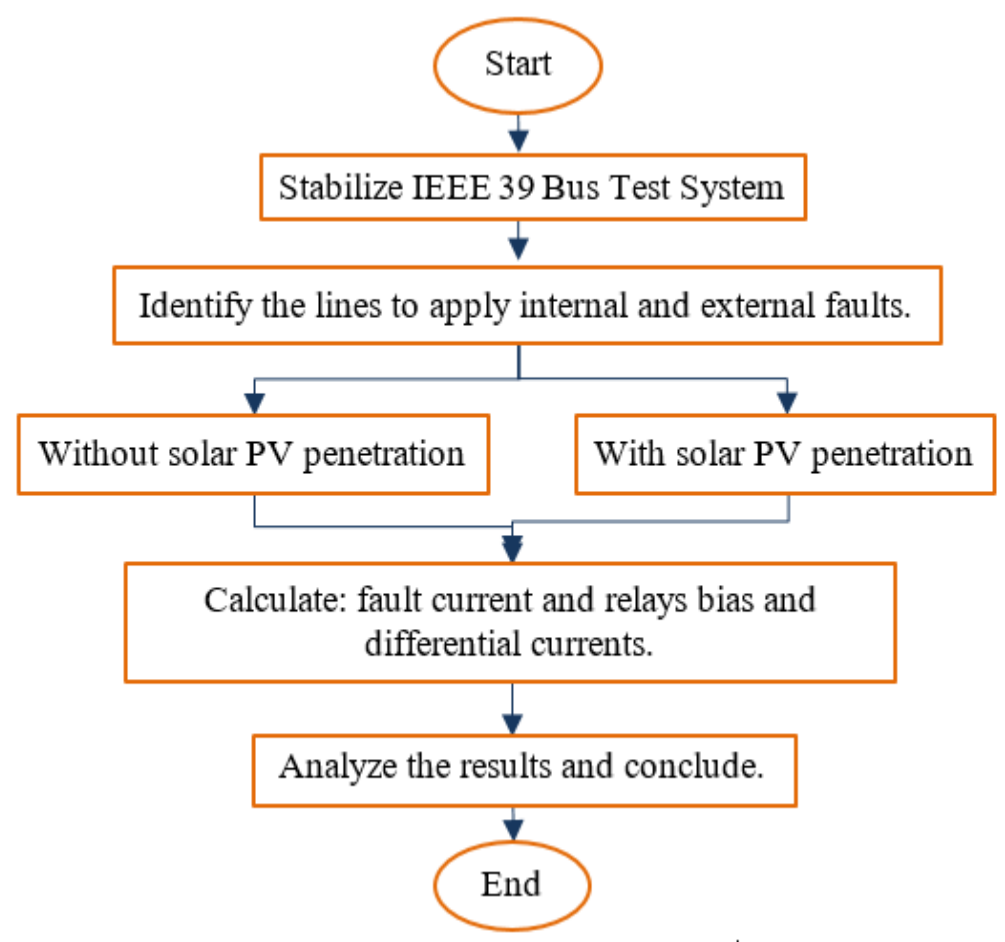

Figure 3. Overall methodology 


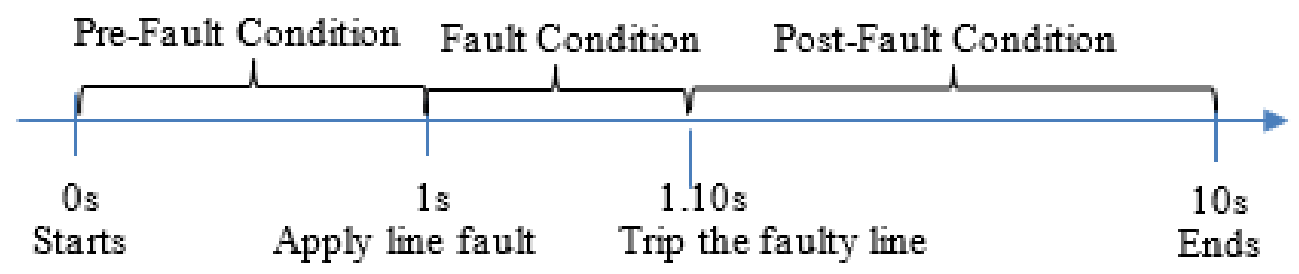

Figure 4. Simulation time line event

Simulations of three phase symmetrical fault are carried out for cases with and without solar PV penetration at the chosen lines. Based on Malaysia Energy Commission for large solar scale (LSS), the maximum solar PV penetration in a network is 50MW; hence, the capacities of solar PV penetration in this research work are 20MW and 40MW, which are within the allowable amount for LSS [27]. The magnitudes of fault current during the sub-transient and transient fault conditions at the faulted and neighboring lines are calculated for all the following scenarios:

a) Scenario 1: Without solar PV Penetration at the Strongest Line

b) Scenario 2: 20MW and 40MW of PV at the Strongest Line

c) Scenario 3: Without solar PV Penetration at the Bottleneck Line

d) Scenario 4: 20MW and 40MW of PV at the Bottleneck Line

e) Scenario 5: Without solar PV Penetration at the Weakest Line

f) Scenario 6: 20MW and 40MW of PV at the Weakest Line

\section{RESULTS AND ANALYSIS}

This section elaborates on the results of the research work; PSS ${ }^{\circledR} \mathrm{E}$ simulation results are presented based on the fault simulation scenarios at selected lines. All the currents at the neighboring lines are monitored during steady state, external and internal faults conditions. Furthermore, the reliability of the protection relay installed at the strongest, bottleneck and weakest lines is analyzed respectively based on the transient current taken at $1.04 \mathrm{~s}$ of the simulation event. This is taking into consideration that 40 second is the time taken for 87PWR a differential relay to operate and send a signal to trip the faulted line [28].

\subsection{Scenario 1 and scenario 2 -analysis at the strongest line-line $7-8$}

Table 1 shows the bias and differential currents of a protection relay installed at Line 7-8, the strongest line for scenarios with and without the presence of solar PV for three different conditions. At steady state condition, bias current decreases with solar PV penetration in the system. Power supply in the system is less dependent on conventional generators with an increment of solar PV penetration. Figure 5 shows the flow of real and reactive power feeding into the fault during the occurrence of an external fault at Line 8-9 without the presence of solar PV. The negative value in differential current reflects the direction of power flow in the system due to the occurrence of external fault. Nevertheless, the relay remains stable at steady state and external fault conditions since the differential current is minimal. During an internal fault condition at Line 7-8, the values of differential and bias currents increase when solar PV capacity is 20MW compared to without solar PV penetration; however, both the currents decrease when the capacity of solar PV is increased to 40MW. This consequence is due to the changes in direction of power flow in the power system network; the import and export power from one area to another change as solar PV injection increases, which depend on the load demand in the connecting areas. Despite of inconsistent in the direction of power flow, the differential current value is significant to operate the protection relay and isolate the fault from the rest of the system.

Table 1. Differential and bias currents in the protection relay installed at the strongest line-line 7-8

\begin{tabular}{ccccccc}
\hline & \multicolumn{3}{c}{ Bias Current, IBIAS $(\mathrm{A})$} & \multicolumn{3}{c}{ Differential Current, IDIFF (A) } \\
Power System Condition & Without & With 20MW & With 40MW & Without & With 20MW & With 40MW \\
& PV & PV & PV & PV & PV & PV \\
\hline Steady State & 0.6448 & 0.5518 & 0.5419 & 0.0035 & 0.0035 & -0.0035 \\
The Most Severe External Fault & 5.9735 & 5.8783 & 5.8765 & -0.0181 & -0.0185 & -0.0191 \\
(Line 8-9) & 9.0825 & 9.2702 & 9.2695 & 18.1652 & 18.5404 & 18.5390 \\
Internal Fault (Line 7-8) & & &
\end{tabular}




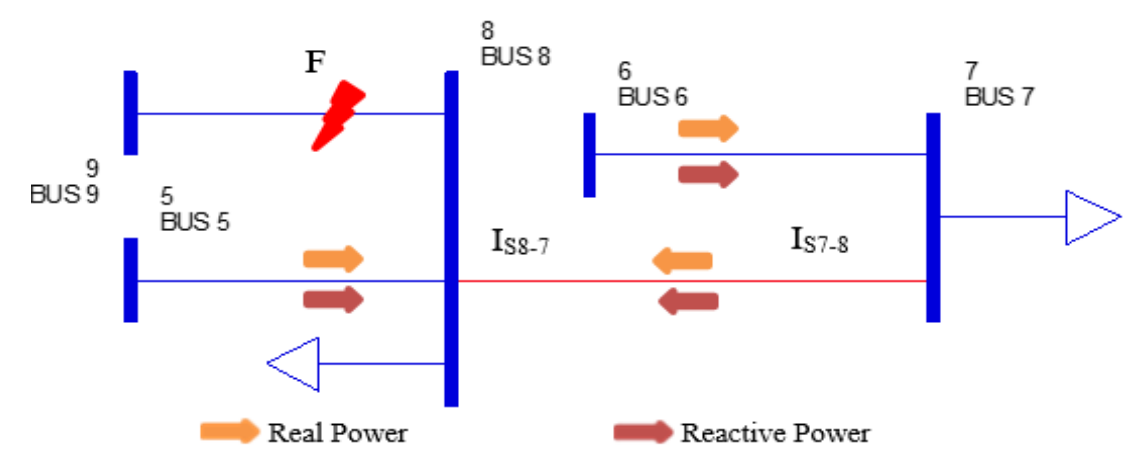

Figure 5. Power flow during external fault at line 8-9 without solar PV penetration

\subsection{Scenario 3 and scenario 4-analysis at the bottleneck line-line 16-19}

Figure 6 shows the real and reactive power flow through the bottleneck line, which is Line 16-19 feeding into the external fault at Line 16-24. The differential and bias currents of the protection relay installed at this bottle neck line are monitored for scenarios with and without the presence of solar PV penetration in the system and tabulated in Table 2. Referring to this table, at steady state condition without and with solar PV penetration, the line is heavily loaded with line loading almost hundred percent. Nevertheless, the differential relay remains stable during steady state and external fault conditions irrespective of without and with solar PV interruption. In contrast, during internal fault conditions, the differential current increases with the increased in solar PV penetration, thus causes the relay to operate irrespective of without or with solar PV penetration.

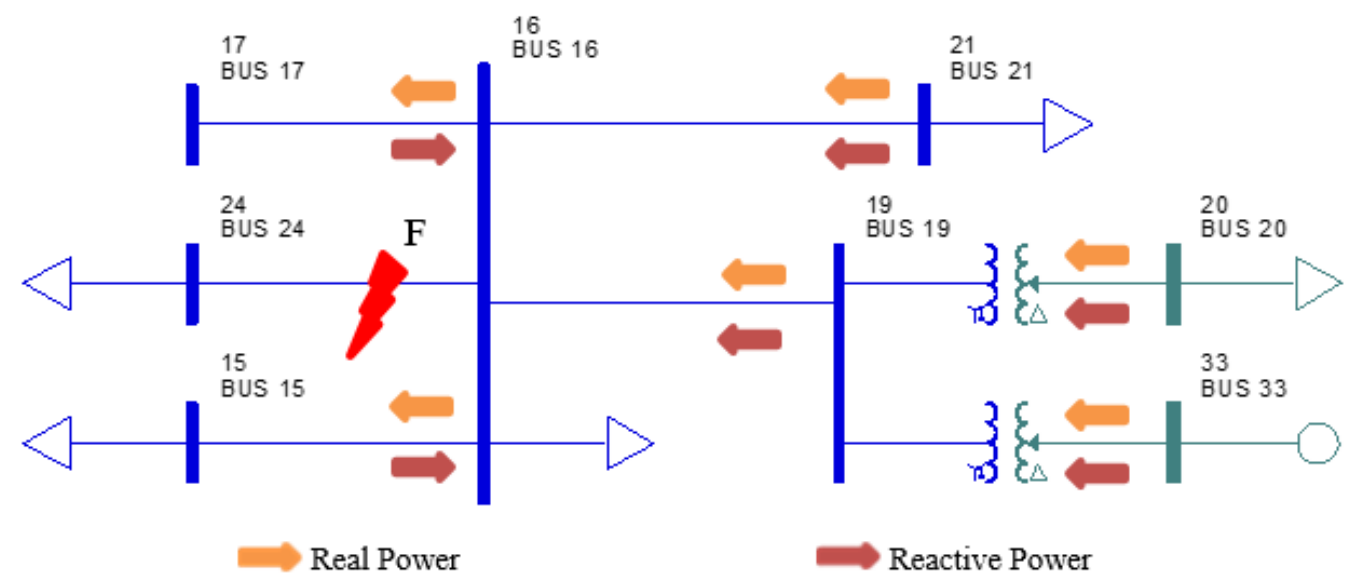

Figure 6. Power flow during external fault at line 16-24 without solar PV penetration

Table 2. Differential and bias currents in the protection relay installed at the bottleneck line-line 16-19

\begin{tabular}{ccccccc}
\hline & \multicolumn{3}{c}{ Bias Current, IBIAS (A) } & \multicolumn{3}{c}{ Differential Current, IDIFF (A) } \\
Power System Condition & Without & With 20MW & With 40MW & \multicolumn{2}{c}{ Without } & With 20MW \\
& PV & PV & PV & PV & PV & PV \\
\hline Steady State & 0.9897 & 0.9839 & 0.9897 & 0.0414 & 0.0017 & 0.0414 \\
The Most Severe External Fault & 1.6370 & 1.6321 & 1.6336 & -0.0112 & -0.2645 & -0.0117 \\
(Line 16-24) & 1.7350 & 1.7527 & 1.7529 & 3.4699 & 3.5053 \\
Internal Fault (Line 16-19) & & & & & 3.5057 \\
\hline
\end{tabular}

\subsection{Scenario 5 and scenario 6-analysis at the weakest line-line 20-34}

Figure 7 shows an external fault for a differential relay protecting the weakest line, Line 20-34; this line is connected to a conventional generator. Bias and differential currents of the protection relay installed at the weakest line without and with the presence of solar PV for the three scenarios are shown in Table 3. 
When an external fault is cleared which means the circuit breaker at Bus 20 trips to disconnect Line 19-20 the only tie line connecting between the conventional generator and other parts of the system. As a result, the generated power can only be supplied to the load at Bus 20. Referring to Table 3, the values of differential current is minimal during steady state and external fault conditions; hence, the relay remains stable. However, when an internal fault occurs at Line 20-34, the conventional generator will be isolated completely from the system after the fault is cleared. The magnitude of differential current is significant and almost double the magnitude of bias current for both without or with solar PV penetration in the power system. Thus, the relay will operate and isolate the faulted line, so as the conventional generator from the power system network.

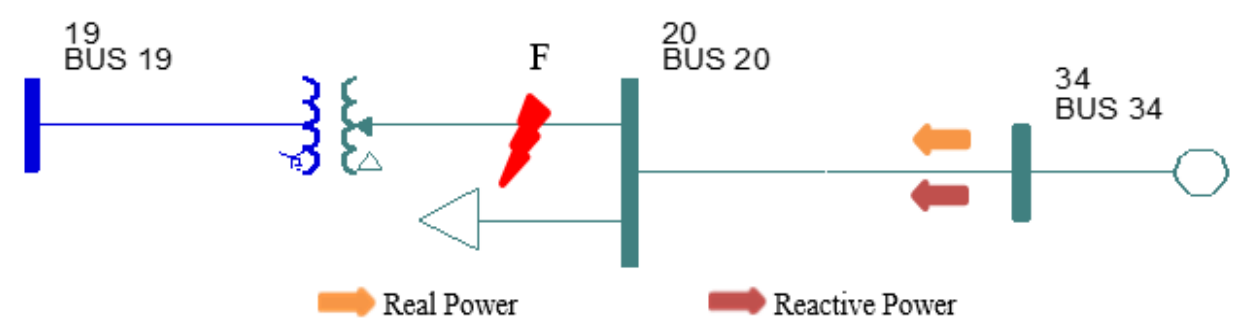

Figure 7. Power flow during external fault at line 19-20 without solar PV penetration

Table 3. Differential and bias currents in the protection relay installed at the weakest line, line 20-34

\begin{tabular}{ccccccc}
\hline & \multicolumn{3}{c}{ Bias Current, $\mathrm{I}_{\text {BIAS }}$ (A) } & \multicolumn{3}{c}{ Differential Current, $\mathrm{I}_{\text {DIFF }}$ (A) } \\
Power System Condition & Without & With 20MW & With 40MW & Without & With 20MW & With 40MW \\
& PV & PV & PV & PV & PV & PV \\
\hline Steady State & 0.8423 & 0.8435 & 0.8424 & 0.0007 & 0.0007 & 0.0010 \\
The Most Severe External Fault & 1.0685 & 1.0588 & 1.0593 & 0.0485 & 0.0489 & 0.0488 \\
(Line 19-20) & 1.2048 & 1.2033 & 1.2036 & 2.4096 & 2.4065 & 2.4072 \\
Internal Fault (Line 20-34) & & & &
\end{tabular}

\section{CONCLUSION}

This research work analyzes the reliability of line differential protection relay for a few different scenarios in IEEE 39 bus test system, with and without the presence of renewable energy. Three phase symmetrical line fault is applied accordingly at the strongest, bottleneck and weakest lines as an internal fault while faults at the neighboring lines are considered as external faults. The currents that flow through the selected lines are monitored during steady state, internal and external faults conditions without and with $\mathrm{RE}$ in the system. The results have shown that the magnitude of these currents are influenced by the direction of real and reactive power flow in the system, the fault location, and the capacity of solar PV penetration in the system. For all scenarios, as solar PV penetrates into the system, the bias currents will increase; this is due to the change of power flow in the system since the import and export power from one area to another change depending on the load demand. Therefore, it is important to monitor the line and fault currents, and analyze the reliability of differential protection relay through simulation especially for power system with RE penetration in maintaining power system stability and reliability to customers. The objective of this research work on evaluating the reliability of line differential protection relay during steady state and fault conditions, without and with solar PV penetration is achieved by simulating steady state and three-phase symmetrical line fault in IEEE 39 bus test system using power system simulation for engineering (PSS®E) software. The potential future research works are designing the specification of current transformer and analysis the performance of current transformer during worst case scenarios.

\section{ACKNOWLEDGEMENTS}

The research team would like to acknowledge the ministry of higher education (MOHE) for the research funding (FRGS/1/2014/TK06/UNITEN/02/9) on 'Optimum renewable energy penetration using Wide Area Intelligent System with consideration towards line loadability, protective relaying performance and self-healing adaptation in maintaining power system stability'. The team would also like to extend acknowledgments to Universiti Tenaga Nasional, Tenaga Nasional Berhad and lecturers for providing the facilities and making this research possible. 


\section{REFERENCES}

[1] S. Baraskar and S. Wadhankar, "Phase comparison techniques for transmission line protection," 2017 International Conference on Energy, Communication, Data Analytics and Soft Computing (ICECDS), Chennai, pp. 325-329, 2017.

[2] S. M. Kouhsari, "Unit Protection Differential Relays," [Online]. Available: http://www.tomcad.com/linkedin/week7powersystemprotection(DifferentialRelays).pdf.

[3] S. Karupiah, M. H. Hussain, I. Musirin, and S. R. A. Rahim, "Prediction of overcurrent relay miscoordination time using urtificial neural network," Indonesian Journal of Electrical Engineering and Computer Science, vol. 14, no. 1, pp. 319-326, 2019.

[4] K. Solak, J. Herlender, and J. Izykowski, "Transmission line impedance-differential protection with improved stabilization for external fault cases," 2018 19th International Scientific Conference on Electric Power Engineering (EPE), Brno, pp. 1-6, 2018.

[5] G. Sivanagaraju, S. Chakrabarti, and S. C. Srivastava, "Uncertainty in transmission line parameters: Estimation and impact on line current differential protection," in IEEE Transactions on Instrumentation and Measurement, vol. 63, no. 6, pp. 1496-1504, 2014.

[6] I. N. Perdana, "Increasing reliability of critical line feeder by upgrading protection using digital technology," 2015 IEEE 5th International Conference on Power Engineering, Energy and Electrical Drives (POWERENG), Riga, pp. 648-652, 2015.

[7] H. Nicorescu, M. Albu, and M. Eremia, "Achieving interoperability of power system protection using SCADA and PMU information,” 2019 8th International Conference on Modern Power Systems (MPS), Cluj Napoca, Romania, pp. 1-4, 2019.

[8] R. Haider and C.-H. Kim, "Chapter 7-Protection of DERs," in Integration of Distributed Energy Resources in Power Systems, Elsevier, pp. 157-192, 2016.

[9] S. K. El-Sayed and H. S. Mohamed, "Enhancing the performance of distance protection relays using interactive control system," Indonesian Journal of Electrical Engineering and Computer Science, vol. 13, no. 1, pp. 411-419, 2019.

[10] S. S. D. Sahel and M. Boudour, "Wavelet energy moment and neural networks based particle swarm optimisation for transmission line protection," Bulletin of Electrical Engineering and Informatics, vol. 8, no. 1, pp. 10-20, 2019.

[11] X. Wang, H. Liu, Z. Zhou, Y. Guo, and D. Du, "A Current Transformer Saturation Identification Method of Transmission Line Based on Current Sample Data," 2017 IEEE Power \& Energy Society General Meeting, Chicago, IL, pp. 1-6, 2017.

[12] V. Lackovic, "10: Unit Protection of Feeders," Network Protection \& Automation Guide, no. 877, pp. 152-169, 2011.

[13] T. Rajić and Z. Stojanović, "An algorithm for longitudinal differential protection of transmission lines," International Journal of Electrical Power \& Energy Systems, vol. 94, pp. 276-286, 2018.

[14] I. C. Borăscu, "The CT behavior and ITS compatibility with relay protection," UPB Science Bulletin Series C Electrical Engineering Computer Science, vol. 76, no. 3, pp. 17-28, 2014.

[15] C. Cem, "Internationale International Standard Cei Part 4-2 : Internationale International Standard," Fondamentale En CEM, 2001.

[16] P. K. Gangadharan, T. S. Sidhu, and A. Klimek, "Influence of current transformer saturation on line current differential protection algorithms," in IET Generation, Transmission \& Distribution, vol. 1, no. 2, pp. 270-277, 2007.

[17] M. M. Abdel Aziz, A. F. Zobaa, D. K. Ibrahim, and M. M. Awad, "Transmission lines differential protection based on the energy conservation law," Electric Power Systems Research, vol. 78, no. 11, pp. 1865-1872, 2008.

[18] P. Dehghanian, B. Wang, and M. Tasdighi, "New Protection Schemes in Smarter Power Grids with Higher Penetration of Renewable Energy Systems," in Pathways to a Smarter Power System, pp. 317-342, 2019.

[19] R. Bayindir, S. Demirbas, E. Irmak, U. Cetinkaya, A. Ova, and M. Yesil, "Effects of renewable energy sources on the power system," 2016 IEEE International Power Electronics and Motion Control Conference (PEMC), Varna, pp. 388-393, 2016.

[20] L. Wang, Y. F. Lin, and S. C. Ke, "Stability analysis of an offshore wind farm connected to Taiwan power system using DIgSILENT," OCEANS 2014-TAIPEI, Taipei, pp. 1-5, 2014.

[21] G. M. Mufti, A. Basit, M. U. Rehman, S. Z. Hassan, and R. A. Khan, "Comparative analysis of the effects of renewable energy integration on the utility grid system," 2018 International Conference on Computing, Mathematics and Engineering Technologies (iCoMET), Sukkur, pp. 1-5, 2018.

[22] Y. J. Liu, Y. H. Tai, C. Y. Huang, H. J. Su, P. H. Lan, and M. K. Hsieh, "Assessment of the PV hosting capacity for the medium-voltage $11.4 \mathrm{kV}$ distribution feeder," 2018 IEEE International Conference on Applied System Invention (ICASI), Chiba, pp. 381-384, 2018.

[23] L. F. Ochoa and D. H. Wilson, "Angle constraint active management of distribution networks with wind power," 2010 IEEE PES Innovative Smart Grid Technologies Conference Europe (ISGT Europe), Gothenberg, pp. 1-5, 2010.

[24] J. Wang, X. Zhu, D. Lubkeman, N. Lu, and N. Samaan, "Continuation power flow analysis for PV integration studies at distribution feeders," 2017 IEEE Power \& Energy Society Innovative Smart Grid Technologies Conference (ISGT), Washington, DC, pp. 1-5, 2017.

[25] M. Z. Mohd Alias, M. J. Homam, and F. H. Mohd Noh, "Review on solar disturbance studies and electric power transmission line fault in Malaysia," Indonesian Journal of Electrical Engineering and Computer Science, vol. 17, no. 1, pp. 118-125, 2019.

[26] F. M. Albatsh et al., "A comparative analysis of line stability indices for dynamic voltage stability," 2017 International Conference on Engineering Technology and Technopreneurship (ICE2T), Kuala Lumpur, pp. 1-6, 2017.

[27] Suruhanjaya Tenaga, "Guidelines on Large Scale Solar Photovoltaic Plant For Connection to Electricity Networks,” Laws Malaysia, vol. 1990, pp. 1-103, 2017.

[28] P. Wire and C. Differential, "7PG21-Solkor R/Rf 7PG21-Solkor R/Rf” 2018. [Online]. Available: https:/cache.industry.siemens.com/dl/files/393/109747393/att_986525/v1/7PG21_Solkor_Rf_Complete_Technical_Manual.pdf. 


\section{BIOGRAPHIES OF AUTHORS}

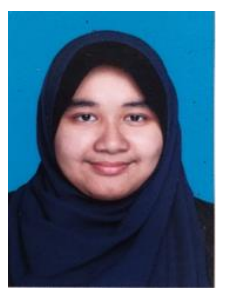

Mas Ewani Binti Mohamed Yusoff obtained Bachelor of Electrical Power Engineering (Hons) in 2016 from Universiti Tenaga Nasional. She is currently pursuing Master in Electrical Engineering in Universiti Tenaga Nasional. The research topic she is currently working on is the analysis and behavior of protective relaying in the power system with the presents of solar photovoltaic.

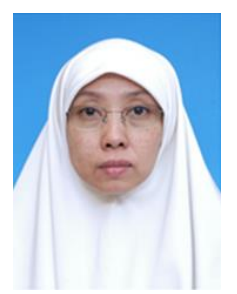

Ir. Dr. Halimatun Binti Hashim obtained BSc in Engineering from Virginia Polytechnic Institute \& State University in 1998, Master in Electrical Engineering from Universiti Tenaga Nasional in 2002, and Doctor of Philosophy in Engineering from Universiti Tenaga Nasional in 2013. She had working experience with Lembaga Letrik Negara, Tenaga Nasional Berhad and Universiti Tenaga Nasional. She is now a Senior Fellow at Universiti Tenaga Nasional; her research areas are on power system stability and power system protection. 